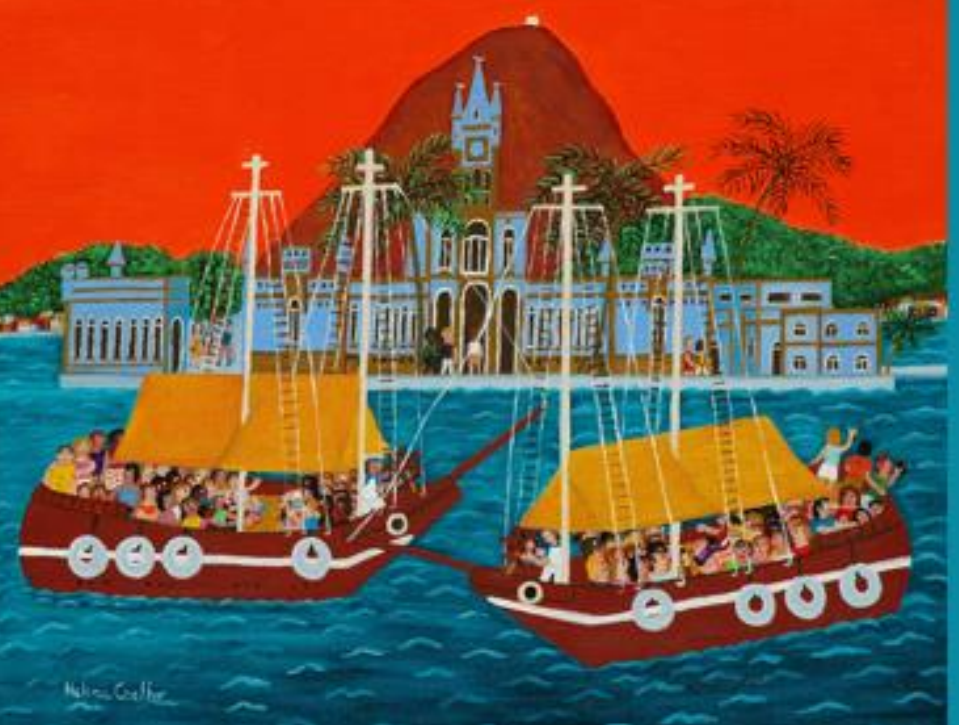

\title{
A RECONSTRUÇÃO DE PERSONAGENS NA TRADUÇÃO DE CONTOS DE CORTÁZAR
}

\section{THE RECONSTRUCTION OF CHARACTERS IN THE TRANSLATION OF CORTAZAR'S SHORT STORIES}

\author{
Cláudia XAVIER FARIA \\ Universidade Federal do Rio Grande do Sul, Brasil
}

\section{Solange MITTMANN \\ Universidade Federal do Rio Grande do Sul, Brasil}

\begin{abstract}
RESUMO | INDEXACC̃̃O | TEXTO | REFERÊNCIAS | CITAR ESTE ARTIGO | AS AUTORAS RECEBIDO EM 11/10/2020 • APROVADO EM 22/02/2021

DOI: https://doi.org/10.47295/mgren.v10i1.2896
\end{abstract}

Resumo

Este trabalho apresenta uma análise da reconstrução de personagens em três contos do escritor argentino Julio Cortázar. Os contos selecionados fazem parte da obra Todos los fuegos el fuego de Julio Cortázar traduzida no Brasil por Gloria Rodriguez como Todos os fogos o fogo. Os contos são "La autopista del sur", "La salud de los enfermos" e "Reunión", traduzidos, respectivamente, como "A autoestrada do sul", "A saúde dos doentes" e "Reunião". O objetivo é observar como se dá a reconstrução de personagens no processo tradutório. Da perspectiva literária, trazemos questões sobre personagens. E com base na perspectiva da Análise do Discurso francesa, consideramos que a tradução é produzida a partir de uma interpretação particular, e é um trabalho autoral no qual o tradutor toma certas decisões tradutórias em conta da sua interpretação e da imagem que faz de seus 
leitores. Concluímos que estas decisões acabam por influenciar a forma como os leitores constroem as personagens.

Abstract

This paper presents an analysis of the reconstruction of characters in three short stories of the Argentinian writer Julio Cortázar. The selected short stories are a part of the collected works Todos los fuegos el fuego by Julio Cortázar translated in Brazil by Gloria Rodriguez. The short stories are "La autopista del sur", "La salud de los enfermos" and "Reunión", translated, respectively, as "A autoestrada do sul", "A saúde dos doentes" and "Reunião". The target is to observe how the reconstruction of characters happens in the process of translation. From the literary perspective, we present issues regarding the characters. And based on the perspective of Discourse Analysis, we consider that translation is produced based on a particular reading, and is an auctorial work in which the translator makes certain decisions taking into consideration his or her own interpretations, and the image that is made of their readers. We conclude that these decisions influence the way readers build the characters.

Entradas para indexação

Palavras-chave: Cortázar. Análise do Discurso. Personagens.

Keywords: Cortázar. Discourse analysis. Characters.

Texto integral

\section{Introdução}

Este trabalho tem por objeto de estudo a tradução de contos do escritor argentino Julio Cortázar, e o objetivo é analisar a reconstrução de personagens. Todos os três contos selecionados fazem parte da obra Todos los fuegos el fuego, de 1966, traduzida no Brasil por Gloria Rodriguez como Todos os fogos ofogo.

A fundamentação teórica deste estudo é a Análise do Discurso de linha francesa, cujos princípios têm servido de base para investigações sobre o processo tradutório por um grupo de pesquisadores brasileiros. Nessa perspectiva, a tradução é considerada um processo discursivo em que o sujeito-tradutor realiza leituras de um determinado texto (texto de partida) baseado em suas condições de produção, que são fatores histórico-sociais e linguísticos, e então produz o texto da tradução (texto de chegada), também em condições de produção específicas.

A tradução abre portas para sentidos diversos e faz com que se produzam novas perspectivas a respeito das personagens de Cortázar, pois as diferentes condições de produção dos textos de partida em relação às traduções em questão fazem com que a tradutora não só realize uma leitura singular como também torne as leituras do seu público-alvo heterogêneas. É importante ressaltar aqui que a heterogeneidade da qual estamos tratando vem tanto do fato de que cada leitor (inclusive a tradutora) produz sentidos a partir de suas próprias condições de produção, quanto do fato de que, em se tratando de uma tradução, haverá diferenças culturais entre o público-alvo do texto de partida e o público-alvo do texto de chegada. 
Uma questão fundamental para a reflexão sobre a tradução é a da subjetividade, já que cada sujeito interpreta de forma singular, ainda que, é claro, muitas leituras se aproximem. Além disso, em todo texto existe uma pluralidade de vozes, pois nenhum discurso surge por si próprio. 0 discurso, que se materializa através do texto, é resultado de outros discursos já existentes, com os quais tem relações de sentido.

É levando em conta esses aspectos que, em nossa pesquisa, partimos do texto (de chegada e de partida) e seguimos em direção ao discurso, onde se dá o processo de produção de efeitos de sentido, marcado pela heterogeneidade, pois como consideramos com Mittmann:

Se na produção do texto de base [texto de partida], a heterogeneidade é disfarçada pela autoria em efeito de unidade e de origem, na leitura pelo tradutor (assim como por qualquer leitor) desfaz-se o efeito de unidade, e a heterogeneidade possibilita a interpretação, refazendo-se, em seguida, o efeito de unidade. (MITTMANN, 2012, p. 73).

Ou seja, o fato de que o discurso sempre remete a outros discursos, o que constitui a sua heterogeneidade, vai de encontro à ideia de uma origem unitária, reconhecendo que origem e unidade são efeitos. E é ao desfazer o efeito de unidade que o tradutor abre as portas para um público maior, em novas condições de produção, tornando possíveis novas leituras em novos processos de produção de sentidos. Mas, ao mesmo tempo, não se pode desconsiderar a produção de um novo efeito de unidade (texto de chegada), que resulta do trabalho de autoria do sujeito-tradutor.

O discurso resulta de um processo discursivo, da combinação das condições de produção com um sistema linguístico. Assim, diferentes sujeitos, que se encontram em cenário histórico-social e ideologia particulares - fatores estes que determinam as condições de produção e o processo discursivo -, além de sistemas linguísticos diferentes, podem produzir diferentes discursos e efeitos de sentido a partir do texto. Como demonstra Monteiro:

0 texto está suscetível a interpretações em uma história, em determinadas condições de produção, e, a partir de uma (ou mais) dessas interpretações, é colocado à mercê de outras leituras, de outras interpretações, em outras condições de produção. (MONTEIRO, 2019, p. 95).

Ou seja, são diversos os fatores que determinam a interpretação dos diferentes sujeitos, e o tradutor, que é também um sujeito-leitor, não poderia estar fora dessas determinações. Mas o tradutor é também um sujeito que vai produzir um novo e único texto, fato que vai caracterizar um novo processo, marcado pelas tomadas de decisão e pelo fenômeno de autoria. Esse é o processo tradutório.

Através da escolha de palavras, o tradutor proporciona deslizamentos de sentido à leitura do seu público-alvo, organizando a heterogeneidade de vozes presentes no discurso e constituindo um novo efeito de unidade. A partir de suas escolhas tradutórias, ele faz com que sejam produzidos sentidos para o texto. E é 
pelo gerenciamento desses fatores que o tradutor se transforma em autor: "Considerando-se a relação entre o assujeitamento e a tomada de posição, temos a construção do efeito de autoria, como efeito de origem, de responsabilidade [...]" (MITTMANN, 2012, p.69).

São as tomadas de posição que definem como o tradutor se coloca no texto, ocultando ou tornando visível a sua leitura, a sua subjetividade. E essas tomadas de posição influem na interpretação dos leitores do texto de chegada.

0 processo de produção de sentidos remete a outros discursos, oriundos das leituras possíveis. Nelas, existe um processo de gerenciamento da heterogeneidade. A leitura do tradutor também funciona assim, mas não podemos esquecer que o tradutor também é responsável por produzir um novo texto, e nele, gerenciar a heterogeneidade contida no processo de produção de sentidos que vai influenciar a leitura do seu público-alvo:

$\mathrm{Na}$ produção de um texto, o autor esquece sua condição heterogênea, apresenta-se como responsável pelo que diz e alinhava a aparência de homogeneidade. Já na produção do texto da tradução, o tradutor busca desdobrar-se, trazendo em si a voz do autor do texto de base e, assim, tende a responsabilizar-se pelo processo de produção do novo texto, mas não pela voz que ali fala, já que esta é imputada ao autor. (MITTMANN, 2014, p. 81).

É o que Mittmann (2012) chama de "tradautoria", para abordar a autoria própria da tradução, que difere da autoria do texto conhecido como "original".

\section{Sobre o autor e os contos}

Julio Cortázar é um autor considerado inovador para o seu tempo. Apesar de terem sido produzidas em condições de produção específicas, suas obras têm um certo nível de atemporalidade, parecendo atuais para o leitor de hoje mesmo tendo sido produzidas na metade do século passado.

Nascido em Bruxelas em 1914, foi registrado na Embaixada da Argentina, e faleceu em Paris, em 1984. Aos 37 anos, mudou para Paris, onde passaria o resto da sua vida, por causa do regime ditatorial que estava se instalando na Argentina, sua pátria.

O espanhol não foi a língua principal nos primeiros anos da infância do autor; mesmo com a passagem da família pela Espanha, até voltarem para a Argentina, país de origem dos pais de Cortázar, durante quatro anos a comunicação se deu quase exclusivamente em língua francesa. Surgia, então, desse contato, um estímulo, digamos, para absorver novas culturas e relacioná-las entre si (BALADÃO, 2017, p. 455).

Em conta disso, ele produziu contos tanto na Argentina quanto na França, de forma que seus contos são destinados a públicos diferentes. É importante afirmar também que as obras de Cortázar ganharam fama no mundo inteiro desde a época do seu lançamento, trazendo leitores de várias realidades para si. Esses leitores, por estarem inseridos em realidades distintas, muitas vezes precisariam de explicações que não estariam explícitas no texto. Considerando tudo isso, pode- 
se imaginar a complexidade do papel dos tradutores ao tentar conciliar tantos mundos diferentes e fazer sentido em cada um deles.

A obra Todos los fuegos el fuego consiste na quarta coletânea de contos de Julio Cortázar. 0 autor, que já estava consolidando um estilo de escrita único, produzia obras que divergiam do estilo literário de outros grandes escritores latino-americanos da época, como Gabriel García Márquez, que eram famosos por escrever romances e contos que eram evidentemente de realismo fantástico. As obras cortazianas também apresentam características do modelo de realismo fantástico, mas essas caraterísticas aparecem de forma mais amena. 0 próprio Cortázar costumava afirmar que a sua escrita era interpretada como fantástica porque as classificações utilizadas para demarcar obras literárias eram limitadas. Porém, ao analisar sua narrativa de forma geral e, especificamente, os três contos aqui selecionados, se torna claro que, em suas obras, Cortázar constrói uma realidade com elementos fantásticos. Em muitos de seus contos, a narrativa começa com a retratação realista de um nicho da sociedade ou de uma situação mundana, e acaba por produzir uma ocorrência tão incrível que só poderia ser tratada como fantástica. Há também outros elementos que reafirmam essa noção, como ilustram Duarte e Correia (2012, p. 46):

As narrativas do escritor argentino apresentam um fantástico sutil com narrativas enigmáticas, dualidades temporais, histórias que cruzam tempo e espaço, narrativas que influenciam na noção de realidade e ficção do leitor, oferecendo ao mesmo aporias da existência da humanidade e do universo [...].

O que ocorre, portanto, é a manutenção de elementos da realidade que suportam ocorrências de ordem fantástica.

O livro em questão está composto de oito contos, quase todos contendo elementos fantásticos. Tal como ocorre em sua obra de maneira geral, em Todos los fuegos el fuego, a ideia de dualidade espaço-temporal e a narrativa que passa do ordinário ao absurdo são recorrentes, e estão presentes, de uma forma ou outra, em todos os contos. A coletânea teve sua primeira edição publicada no ano de 1966.

Neste estudo, fizemos um batimento entre os contos em língua espanhola, tomados da edição de 2013 da editora Punto de Lectura, e os em língua portuguesa, traduzidos por Gloria Rodriguez - também tradutora de outra coletânea do mesmo autor: Histórias de Cronópios e de Famas -, edição de 2011 da editora Best Bolso.

\section{Análise}

No livro A personagem de ficção, Candido et alii (2011) mencionam três elementos principais para o desenvolvimento de uma novela: o enredo, a personagem, e as ideias e, sobre isso, fazem a seguinte afirmação: "No meio deles (enredo e ideias) avulta a personagem, que representa a possibilidade de adesão afetiva e intelectual do leitor, pelos mecanismos de identificações, projeção, transferência etc." (CANDIDO et al., 2011, p. 39); ou seja, é dada a importância da personagem para a narrativa, uma vez que ela cativa o leitor e faz com que ele se 
envolva com o texto. E é esse envolvimento que faz com que o leitor se coloque na posição de autor, produtor de sentidos em uma perspectiva particular sobre os elementos da narrativa, dentre eles os personagens. A adesão é responsável por produzir diferentes leituras e diferentes formas de pensar as personagens, mas ela é direcionada pelas condições de produção de leitura do texto traduzido, que são tanto os elementos que fazem com que ela ocorra, quanto os elementos que delimitam o modo como o sujeito vai pensar a personagem a partir da leitura. $\mathrm{Ou}$ seja, as condições de produção indicam se - e como - o sujeito vai se identificar com a narrativa, e tornam possível para o mesmo traçar a linha que define as personagens de uma maneira que para ele seja acessível. Com relação a esse processo, é importante ressaltar que a adesão será gerenciada pelo tradutor, que vai analisar essas condições de produção, prevê-las, e produzir um texto que atenda às necessidades do seu público-alvo. Por isso a importância do papel do tradutor, é ele que vai garantir que os seus leitores tenham acesso ao texto traduzido ao manejar os elementos que marcam o processo de leitura dos mesmos.

A partir disso, pode-se imaginar que, diante de tantas interpretações, as personagens, antes conceitos fechados e já delimitados pelo autor, acabam se modificando até se tornarem algo novo e único, e isso ocorre diante de cada uma das leituras de cada sujeito. Ou seja, o processo de construção de personagens está nas mãos de cada leitor, e escapa ao autor do texto de partida. Sobre a construção de personagens, Brait (1985, p. 67) se pronuncia da seguinte maneira: "ele [o autor] vai manipular o discurso, construindo essas criaturas, que, depois de prontas, fogem ao seu domínio e permanecem no mundo das palavras à mercê dos delírios que esse discurso possibilita aos incontáveis receptores". Estamos tratando de um sentido que escapa ao autor, e ao tradutor, pois este se colocará na posição de autor quando produz um texto novo, e constrói também estas personagens, resultado dos processos de leitura e tomada de posição.

Para promover uma análise da obra de Cortázar, levando em conta o que está sendo apontado, foram selecionados três contos de uma mesma coletânea. Fatores como o deslizamento de sentidos que ocorre no processo de produção da obra traduzida, as mudanças de forma que afetam a percepção do público-alvo do texto de chegada, a inclusão de nodas de rodapé e a tradução de prefácios demonstram como obras de diferentes condições de produção podem ser interpretadas por diferentes tipos de leitores, com um enfoque especial nos leitores do texto de chegada, a partir da produção dos efeitos de sentido do texto.

O conto "La autopista del sur" / "A autoestrada do sul" tem um certo nível de realismo fantástico. Ele relata um imenso engarrafamento em uma autoestrada no sul da França, e como isso afeta a vida das várias pessoas que estavam nesse engarrafamento, focando mais especificamente em um grupo de personagens e em seus carros. Os personagens são identificados pelas marcas dos carros em que se encontram. Por isso, é importante que o leitor esteja a par dos modelos de carro presentes no conto, para que ele entenda assim os seus personagens. Porém, um leitor que não conheça muito sobre modelos de carro antigos (o conto em espanhol foi publicado pela primeira vez em 1966, portanto existe um grande abismo temporal entre essa época e os dias atuais) pode ter uma certa dificuldade em reparar as características das personagens a partir disso, como, por exemplo, o valor do carro e o status social do motorista. E, como não era possível fazer uma 
nota de rodapé explicando o modelo de cada carro que aparece no conto, a consequência para o leitor é que a caracterização das personagens fica menos evidente.

Por exemplo, a primeira personagem a ser descrita no conto é a "Moça do Dauphine", uma jovem solteira que mais tarde se envolve com o engenheiro, e que está representada por um carro que era concorrente do Fusca nos anos 60, ou seja, um carro popular, clássico, que combinava com o perfil de jovem viajante solteira e desejada. Esse carro se opõe aos modelos de carros de família, como o 203, e outros carros como o Simca, modelo não especificado de uma marca criada para ser comercializada na França sem taxas de importação, ou seja, uma alternativa de carro barata para os dois jovens retratados no conto. Esse tipo de descrição, se pudesse ter sido incluída no texto, faria com que o leitor se familiarizasse melhor com o perfil de cada personagem. Ao mesmo tempo, pode-se perceber que o fato de esse conflito existir é uma prova de que a gama de leitores cortazianos cresceu.

O conto seguinte se chama "La salud de los enfermos" / "A saúde dos doentes" e trata de uma família na qual a matriarca sofre de uma doença grave e deve ser poupada de qualquer tipo de sofrimento, incluindo receber notícias ruins. As coisas se complicam quando o filho da enferma morre em um acidente de carro e a família se desdobra tentando ocultar o ocorrido. Ao longo do tempo, mais uma tragédia surge, a doença de uma tia, e se torna cada vez mais difícil alienar a matriarca de tudo que está acontecendo.

A partir deste conto, pode-se analisar as escolhas de tradução e suas consequências no que diz respeito à construção dos personagens. Por exemplo, no texto de partida, quando se fala do acidente de carro que matou Alejandro, o autor usa a expressão "se había matado", dando a entender que Alejandro tem um certo grau de responsabilidade no ocorrido. A escolha da tradutora causa um deslizamento de sentido, já que a tradutora usa o termo "morrera" para substituir a expressão do texto de partida, o que não sinaliza que Alejandro pudesse ter responsabilidade sobre o ocorrido. Isso acaba por modificar parte da construção da personagem Alejandro no conto, indicando-o ou não como alguém um tanto imprudente.

Mais adiante, no mesmo conto, existe outra construção que foi modificada na tradução. Quando se fala na personagem Maria Laura, logo após a morte de Alejandro, no texto de partida o narrador diz que "Hasta Maria Laura, mas allá de toda compreensión en esas primeras horas, había admitido que no era posible darle la notícia a mamá." No texto de chegada, Rodriguez escolhe afirmar que Maria Laura estava "incapaz de qualquer compreensão naquelas primeiras horas". No texto de partida, o autor ilustra a situação na qual Maria Laura se encontrava, uma situação que dizia respeito à tragédia que havia ocorrido. 0 termo "mas allá" tem o equivalente em português "além", mas a tradutora optou por não fazer uma tradução literal e utilizar o termo "incapaz". Porém esse termo acaba por modificar a ideia que temos da personagem, já que o termo "mas allá" indica que a situação como um todo foi muita informação para Maria Laura assimilar, e o termo "incapaz" pode ter dois sentidos: o primeiro, que concorda com o termo "mas allá"; e o segundo, que indica que Maria Laura seria incapaz de compreender o que estava acontecendo por outros motivos, talvez uma limitação da própria personagem. 
Chegando no final do conto, existe uma situação na qual a personagem Tio Roque fala com a personagem Mamãe e diz a ela a seguinte frase: "Te han salido unos hijos que valen la pena". Esse trecho indica que ele estaria elogiando os filhos dela e elogiando a ela pela criação que deu a eles, porque a expressão "te han salido" pode ser relativa a como os filhos saíram na criação, o que dá à personagem Mamãe a responsabilidade pelo êxito dos filhos. Para traduzir esse trecho, a tradutora escolheu fazer Tio Roque dizer a Mamãe "Você tem uns filhos ótimos", e a responsabilidade da mãe com relação à criação dos filhos não é apontada no texto de chegada.

Passando adiante, na mesma coletânea, temos o conto "Reunión" / "Reunião", que trata da descrição de momentos que ocorreram após uma das inúmeras batalhas de Che Guevara. 0 conto é narrado por Che Guevara, e mostra o ponto de vista de um combatente revolucionário e de suas preocupações relativas à revolução.

Selecionamos uma nota de rodapé posta no texto de chegada, localizada em um momento da narrativa que ilustra os desafios pelos quais a personagem principal está passando e os seus pensamentos a respeito. A nota da tradutora define o termo "diádocos": "na Macedônia, os generais de Alexandre, o Grande, que, após a morte deste, disputaram entre si o seu império". A explicação nos mostra uma preocupação da personagem em relação ao futuro da sua luta, mostrando o quanto ele não queria que o seu companheiro Luís, líder da revolução, morresse e deixasse a ele (Che) e aos seus outros companheiros, tentando manter vivo o seu "império". Sem a nota, não seria possível à maioria dos leitores a compreensão desse pensamento da personagem principal. A nota da tradutora possibilita que mais leitores tenham uma melhor compreensão da angústia por que passava a personagem durante os acontecimentos da narrativa.

Nesse conto, percebe-se que a escolha tradutória de Gloria Rodriguez possibilita que os leitores do texto de chegada tenham um maior acesso ao texto. É a ideia de acessibilidade de diferentes leitores a diferentes cenários literários, a força que os engloba e apresenta a um mundo tão novo quanto possível.

Porém há momentos em que não há como romper determinadas barreiras que influem na leitura de diferentes sujeitos, o que causa um certo estranhamento. É o que ocorre no caso de "La autopista del sur" / "Autoestrada do Sul", quando os personagens, nomeados e descritos através de seus carros, não são compreendidos por leitores que não são da época de lançamento da primeira edição do texto, época em que tais modelos de carros eram conhecidos pelo público geral. Em grande parte das vezes, essa barreira que permanece se dá unicamente pelo fato de que vivemos em um mundo plural, e que é impossível tratar de diferentes línguas e épocas sem reconhecer suas peculiaridades, traços estes que não podem ser apagados.

Cabe ainda considerar que as condições de produção em que os leitores produzem suas leituras determinam o modo como tecem os fios do seu discurso. Elas vão determinar as formas e limites dessa (re)construção de personagens a cada leitura. 0 tradutor também produz a sua leitura a partir das suas próprias condições de produção. Mas, diferentemente dos outros leitores, ele tem a responsabilidade de produzir um novo texto a partir disso, de gerenciar as diferentes vozes contidas na sua leitura do texto de partida, trazendo novos 
elementos à tona, e reorganizando os elementos antigos com o objetivo de que o seu leitor se sinta contemplado pela nova obra. Como afirma Henge (2015, p. 34):

0 processo tradutório, portanto, não diz respeito à simples relação Uת entre textos que se dá pelo trabalho do tradutor. Considerar a no texto, ou ainda a voz do autor, convoca pensá-las a partir da concepção de língua em $\mathrm{AD}$, materialidade do discurso e sujeita à falha como lugar do equívoco, bem como a questão da interpretação como gesto, como prática material. Esses pontos, de fato, redimensionam a questão da tradução.

É daí que vem a importância de considerar a tradução como um processo e o tradutor como autor. A partir dessa responsabilidade vem a autoria, um processo de gerenciamento de sentidos, processo esse que se demonstra necessário uma vez que não existe uma única retórica oriunda de um único lugar, assim como não existe um único tipo de público que vai ter acesso ao texto. Pode até ser do interesse do autor se direcionar para um perfil específico de leitor, movimento esse que ocorre frequentemente, mas nenhum texto foge ao alcance de um grupo cada vez mais amplo de pessoas. E é nesse cenário que se dá a importância do papel do tradutor, pois é ele quem torna possível que futuros leitores que não têm acesso à língua do texto de partida possam entrelaçar os fios do discurso na leitura do texto de chegada.

Existem inúmeras possibilidades, que surgem da leitura de cada sujeito, mas o movimento que o tradutor faz, ao escolher uma palavra ou outra, faz parte de um cenário que contém diversos movimentos de tomada de posição. 0 efeito de unidade é quebrado, o que pode produzir outras unidades, as leituras de cada sujeito. "A construção do novo se dá sobre o que retorna, sob o efeito de que não é um retorno, mas um original" (MITTMANN, 2014, p. 81). E a responsabilidade de trazer um texto coeso, tanto para com o autor quanto para com o público-alvo, está presente no ato tradutório. 0 tradutor vai se deparar com alternativas possíveis, e o modo como ele responde a elas vai produzir uma abordagem única, diferente das demais abordagens de outros tradutores, visto que cada uma delas é produzida a partir de uma leitura singular em condições de produção específicas.

Pode-se perceber, portanto, que a leitura do tradutor é o que possibilita a discussão a respeito da acessibilidade mencionada anteriormente, uma vez que é a obra do tradutor que abre portas para um novo público-alvo, realizando o seu trabalho de acordo com as abordagens e critérios que para ele funcionam melhor e de acordo com as condições de produção referentes à sua leitura. É o momento da tomada de posição, que vai inevitavelmente influenciar a leitura dos novos sujeitos do discurso. E tudo começa a partir do momento em que o tradutor se coloca como autor de um novo texto. Segundo Henge (2015, p. 36), "tomar posse do dizer seria a tomada de posição primeira do sujeito-tradutor, uma vez que parte de formações imaginárias do lugar de onde fala, do próprio texto lido, a língua em que ele fora escrito, bem como da língua para qual será traduzido... tudo isto determina de forma constitutiva o gesto de interpretação". É a partir da decisão de ocupar a posição de autor que o tradutor acaba por propagar a sua interpretação, 
reforçando o seu olhar marcado pela subjetividade ao mesmo tempo em que possibilita outras leituras, também únicas.

No caso das traduções de Gloria Rodriguez, vemos que certas decisões com relações a certas construções frasais levam a diferentes efeitos de sentido para os seus leitores, e, consequentemente, uma nova construção de personagem, como é o caso do conto "La salud de los enfermos" / "A saúde dos doentes", com as personagens de Mamãe, Alejandro e Maria Laura. Outro exemplo, já antes mencionado, é a falta de notas de rodapé explicando os modelos de carros no conto "La autopista del sur" / A autoestrada do sul", um conto onde as personagens são justamente caracterizadas pelos seus carros, apesar de ter sido apontado que o uso das notas de rodapé nesse caso acabaria fazendo com que o texto perdesse a sua clareza. E, no conto "Reunión" / "Reunião", no momento em que a tradutora escolhe colocar uma nota de rodapé que não constava no texto de partida para explicar uma questão que não era relativa à língua. São tomadas de posição significativas, e demonstram o estilo próprio de Gloria Rodriguez como tradutora.

\section{Considerações finais}

As escolhas tradutórias que apontamos nos três contos podem conduzir a algumas reflexões a respeito de noções que são objeto de estudo da Análise do Discurso, como o fato de que o discurso é um efeito de sentidos numa interlocução - autor-leitor, autor-tradutor, tradutor-leitor. Dessa forma, podemos perceber que no caso das traduções de Gloria Rodriguez para o português brasileiro dos contos de Cortázar, o discurso que começa a partir do próprio Cortázar na produção dos seus contos, de fato, teve início antes, em uma rede de discursos a que o autor teve acesso. E tem a sua continuação na interlocução de Gloria Rodriguez como leitora e tradutora, seguindo seu curso à medida que cada sujeito que se encontra dentro do universo do público-alvo dessa mesma tradução realiza uma leitura própria, o que gera diferentes leituras e perspectivas.

Como tradutora, Gloria Rodriguez gerencia as diferentes vozes e sentidos com vistas a seu público leitor. É a ocorrência da função-tradutor, baseada na responsabilidade que cai sobre os ombros dos mesmos, que devem agir como leitores e como autores, pois a tradução é de sua autoria. Por outro lado, Rodriguez ainda aparece no texto através da voz de Cortázar.

Efeitos de sentidos são produzidos tanto pelo autor, como pelos leitores do texto. São sentidos possíveis em condições de produção das leituras. Assim, cada um desses interlocutores, sejam eles profissionais da tradução ou não, vão produzir leituras subjetivas. Tal subjetividade vai determinar o processo de reconstrução de personagens. Essa ideia é apontada ao se debater o conceito de autoria, desenvolvido a partir da produção das diversas leituras que produzem sentido e, portanto, colocam o interlocutor na posição de sujeito. Para o tradutor, uma responsabilidade está presente na produção da tradução, a partir de uma interpretação pessoal, e é um trabalho autoral no qual o autor (nesse caso o tradutor) realiza certas escolhas tradutórias em conta da sua interpretação e das pesquisas realizadas. A abordagem de cada tradutor vai ser singular, e vai fazer com que os mais diversos leitores se tornem sujeitos do discurso. 
Essas novas condições de leitura e novos efeitos de sentidos produzidos nos leva a pensar os personagens do texto de chegada como reconstruções dos personagens do texto de partida: são os mesmos, mas também são fruto das tomadas de posição da tradutora, e são fruto da leitura dos novos leitores.

\section{Referências}

BALADÃO, Janaína de Azevedo. Todos os tradutores o tradutor: literatura e tradução na obra de Julio Cortázar. Letras da Hoje, Porto Alegre, v. 52, n. 4, p.454-465, 2017.

BRAIT, Beth. A personagem. 3. ed. São Paulo: Ática, 1985.

CANDIDO, Antonio et al. A personagem de ficção. 2. ed. São Paulo: Perspectiva, 2011.

CORTÁZAR, Julio. Todos los fuegos el fuego. In: CORTÁZAR, Julio. Cuentos completos/2. 2. ed. Buenos Aires: Punto de Lectura, 2007. p. 177-322.

CORTÁZAR, Julio. Todos os fogos o fogo. Edição de bolso. Tradução de Gloria Rodriguez. Rio de Janeiro: Editora Bestbolso, 2011.

DUARTE, Laila Karla Lima; CORREIA, Heloisa Helena Siqueira. O estranhamento cotidiano: uma leitura dos contos de Julio Cortázar. Caderno Seminal Digital UERJ, Rio de Janeiro, ano 18 , v. 17, n. 17, p. 46-52, jan./jun. 2012. Disponível em: http://www.epublicacoes.uerj.br/index.php/cadernoseminal/article/view/11000. Acesso em: 13 jun. 2020.

HENGE, Gláucia da Silva. Feitos e efeitos discursivos no processo tradutório do literário: uma discussão sobre o fazer tradutório da obra Pride and Prejudice de Jane Austen. 2015. Tese (Doutorado em Estudos da Linguagem) - Programa de Pós-Graduação em Letras, Universidade Federal do Rio Grande do Sul, Porto Alegre, 2015.

MITTMANN, Solange. Tradautorias de cien años de soledad. Organon, Porto Alegre, n. 53, p. 65-78, 2012.

MITTMANN, Solange. 0 urdume e a trama: a tradautoria sobre a heterogeneidade. In: MACHADO, I. L. et al. (Org.). Autoria: nas malhas da heterogeneidade enunciativa. Curitiba, 2014. p. 81-92.

MONTEIRO, Evandro Oliveira. A Pál Utcai Fiúk: história, historicidade e memória. 2019. Dissertação (Mestrado em Letras) - Programa de Pós-Graduação em Letras, Universidade Federal do Rio Grande do Sul, Porto Alegre, 2019.

\section{Para citar este artigo}

XAVIER FARIA, Cláudia; MITTMANN, Solange. A reconstrução de personagens na tradução de contos de Cortázar. Miguilim - Revista Eletrônica do Netlli, Crato, v. 10, n. 1, p. 151-162, jan.-abr. 2021. 
Cláudia Xavier Faria é bacharelanda em Letras - Língua Portuguesa-Língua $\sqrt{ }$ Espanhola na UFRGS. ORCID: https://orcid.org/0000-0002-4239-5261.

Solange Mittmann é doutora em Letras pela UFRGS e professora do Instituto de Letras e do Programa de Pós-Graduação em Letras da UFRGS. ORCID: https://orcid.org/0000-0001-7959-2894. 